DOI: $10.22559 /$ folklor.975

Folklor/edebiyat, cilt:25, say1: 97-1, 2019/1

\title{
Öğretmen Adaylarının Akademik Erteleme Davranışlarının İncelenmesi
}

\section{A Study on Academic Procrastination Behaviors of Teacher Candidates}

Hande Mişe*

\begin{abstract}
Ahmet Hakan Hançer**
$\ddot{O} \mathbf{z}$

Araştırmada, öğretmen adaylarının akademik erteleme davranışlarının farklı değişkenlere göre incelenmesi amaçlanmıştır. Öğretmen adaylarının akademik erteleme durumları ile ilgili etkenlerin belirlenmesi, onların bu sorunlarını daha iyi tanımalarına ve çözüm önerileri üretmeleri konusunda yardımcı olabileceği düşünülmektedir. Araştırma, tarama modelinde betimsel bir çalışmadır. Araştırmanın evrenini, Cumhuriyet Üniversitesi Eğitim Fakültesinde öğrenim gören öğretmen adayları oluşturmaktadır. Örneklemini ise 2017-2018 eğitim öğretim yılında söz konusu fakültede öğrenim gören Fen Bilgisi, Türkçe, Sosyal Bilgiler ve Sınıf öğretmenliği anabilim dallarında öğrenim gören 263 öğretmen adayı oluşturmaktadır. Öğretmen adaylarının akademik erteleme davranışlarııı belirlemek amacı ile "Akademik Erteleme Ölçeğì" kullanılmıştır. Elde edilen verilerin analizinde ise frekans, ortalama ve standart sapma değerleri ile tek yönlü ANOVA analizi kullanılmıştır. Yapılan analizler sonucunda, öğretmen adaylarının akademik erteleme puanlarının ortalamanın üzerinde olduğu, fen bilgisi öğretmen adayları ile sosyal bilgiler öğretmen adayları arasında anlamlı düzeyde fark olduğu benzer şekilde öğretmen adaylarının cinsiyete göre akademik erteleme puanları arasında da anlamlı bir fark olduğu görülmüştür. Öğretmen adaylarının başarı puanları ve ikamet ettikleri yer (Ailesinin yanı, yurt veya pansiyon, ev) ile akademik erteleme puanları arasında anlamlı bir fark olmadığı yönünde sonuçlara ulaşılmıştır.
\end{abstract}

Anahtar sözcükler: öğretmen adayları, akademik erteleme, akademik başarı, ikamet yeri, cinsiyet

\begin{abstract}
This research aims to review of academic procrastination behaviors of teacher candidates based on different variables. Determination of factors impacting academic procrastination attitudes of teacher candidates will help them to better understand these problems and to offer solutions. The research is based on descriptive survey model. Target population of the study is consisted of teacher candidates attending to the Faculty of Education at Cumhuriyet University. Sampling covers 263 teacher candidates who attend to the Science, Turkish Language, Social Sciences and Classroom Teaching Departments of the abovementioned faculty in the academic year of 2017-2018. "Academic Procrastination Scale" was used
\end{abstract}

\footnotetext{
* Yük. Lis. Öğ., C.Ü Eğitim Fak. Fen Bilgisi Eğitimi Anabilim Dalı, hhandemische@gmail.com

${ }^{* *}$ Doç. Dr., C.Ü Eğitim Fak. Fen Bilgisi Eğitimi Anabilim Dalı, ahhancer@gmail.com
} 
to determine academic procrastination attitudes of teacher candidates. Frequency, means and standard deviation values and one-way ANOVA analysis were used to analyze the obtained data. As a result of the analyses, it is concluded that the academic procrastination scores of the teacher candidates are above the average and there is a significant level of difference between science teacher candidates and social sciences teacher candidates and also the academic procrastination scores of the teacher candidates differ significantly based on gender. It is concluded that there is no significant difference between academic achievements and places of residence of teacher candidates (with family, dormitory or guest houses, houses) and academic procrastination scores.

Keywords: teacher candidates, academic procrastination, academic succes, residence, gender

Giriş

Hedefe ulaşmada en etkin yol ertelemeleri bir kenara bırakmaktır. Neyi, niçin ve nasıl istediğini bilen ama amacını bir türlü eyleme geçiremeyen kişiler atalet içinde yaşayan kişilerdir. Her ne kadar hedefe ulaşma ve başarma fikri bize haz verse de bu fikri eyleme geçirmek adına bir harekette bulunmak istemeyiz ya da bilinçaltımızdan yapmak zorunda olduğumuz bu hareket eylemini öteleriz. İngilizce de “procrastination” kavramına karş1lık gelen bu ötelediğimiz hareket eylemi dilimizde erteleme, geciktirme son ana bırakma davranışı olarak karşımıza çıkmaktadır. Ertelemenin ortak bir tanımı olmamakla birlikte araştırmacıların bu olgu hakkında ortak bir düşünceye sahip olmadıkları görülmektedir. (Ferrari, Johnson and McCown, 1995). Öyle ki Schouwenburg (2004) ertelemeyi, istenilen alternatif bir etkinlik yapılması olarak tanımlamış, tembellik yapma ile eş anlamlı tutulmaması gerektiğine değinmiştir. Chu and Choi (2005) ise ertelemeye meyilli kişileri vakit kaybetme eğilimi gösteren uyuşuk insanlar olarak nitelemiştir.

Erteleme davranışı kademeli olarak bireyin tüm hücresini sarar ve kişi, etkisini cezbedici özelliğinden dolayı anlamakta güçlük çeker. Bazı kişiler için çekici bir davranış olan erteleme alışılmış bir aktivite haline gelebilir (Sadeghi, Hajloo and Emami, 2011). Ertelemenin çekici özelliğinin yanı sıra bir başka özelliği de bazı hedeflerin ertelemeye olan yatkınlığından ileri gelmesidir. Lay (1986) ertelemenin özelliği kapsamında, ulaşmak için gerekli olan bazı hedeflerin ertelenmeye olan yatkınlığına dikkat çekmiştir. İnsanlar erteleme olgusuna oldukça kötümser bakmakta ve olumsuz karakter özelliği olarak görmektedirler. Briody (1980), insanların ertelemeyi kötü, zararlı ve aptalca olarak nitelendirdiklerini söyleyerek bu fenomenin sevilmediğine vurgu yapmıştır. Ertelemenin tanımında ortak bir düşünceye sahip olunmadığı (Ferrari, Johnson and McCown, 1995), gibi ertelemenin sınıflandırılmasında da bir görüş birliği sağlanamamıştır. Chu and Choi (2005) bütün erteleme davranışlarının olumsuz etkiye sahip 
olma olasılığına değinerek iki tip erteleme davranışını ayırt ettiklerini söylemişlerdir: Pasif ve aktif erteleme.

Yine yapılan çalışmalar incelendiğinde 4 farklı erteleme türünün varlığından söz edilir.

1. Son dakikaya kadar akademik görevlerin ertelenmesi (ödev) olarak bilinen erteleme (Milgram ve diğ. 1998)

2. Zamanında yapılmayan ve arka plana itilen, zor planlama gerektiren günlük rutin işlerde erteleme (Lay, 1986; Milgram et al., 1998)

3. Karar vermeyi erteleme (Gülebağlan, 2003)

4. Karar verme ve yerine getirmenin ertelenmesi olarak bilinen işlevsel olmayan erteleme davranışı (Ellis and Knaus 1977, Akt. Steel 2007).

Steel (2007) ertelemenin negatif farkındalık olmasına dikkat çekerek erteleme tanımını istenilen eylem olgusunun kasıtlı olarak ertelenmesi şeklinde ifade etmiştir. Erteleme davranışının altında yatan birçok sebep olmakla birlikte bu sebepler kişinin yaşamını negatif yönde etkilemekte ve O’Brien (2002) ertelemecilerin \%95'inden fazlası bunu azaltmak istemektedir. Hedefe ulaşmak için ne yapması gerektiğini bilen, işlerini nereden başlayıp nasıl bitireceğini tahmin eden, yapmaması durumunda neler kaybedeceğinin farkında olan ama yine de bir türlü amaca yönelik eyleme geçemeyen kişiler erteleme tuzağında çırpınan mükemmeli arama bahanesine gizlenen kararsız kimliklerdir. Durmadan hedef koyan, planlar yapan ama üşenip erteleyen atalet sahibi çoğu birey de kendi içinde erteleme sebeplerine göre dallara ayrılmış konumdadır. Erteleme eğilimi üzerine yapılan araştırmalara göre bu nedenler: beceri, öz yeterlik inaçları, mantıksız düşünceler, başarısızlıktan korkma, zamanı yönetme becerisinin olmayışı, gerçekçi olmayan beklentiler, problem çözme becerileri, kişisel özellikler (mükemmeliyetçilik, sorumluluk), hedeflerin yönlendirilememesi, kendine saygı, endişe ve çalışma alışkanlıklarıdır (Alexander and Onwuegbuzie, 2007; Aydoğan, 2008; Balkıs, 2007; Çakıc1, 2003; Ferrari et al., 2007; Howell and Watson, 2007).

Erteleme davranışı çok sık karşılaşılan fenomen bir davranış olmakla birlikte bu araştırmanın da konusu olan akademik erteleme bu fenomen davranışın alt boyutlarından birisidir. Solomon and Rothblum (1984) ertelemede akademik erteleme durumunu öğrencinin görev ve sorumluluklarını içeren ödev, proje gibi çalışmaları geciktirmesi, akademik görevlerini son ana bırakması şeklinde ifade etmiştir. Rosario et al. (2009) erteleme tüm günlük aktivitelerin içinde var olmasına rağmen okulda yapılacak iş ve görevlerin daha sık olması, okullardaki erteleme davranışını günlük yaşamdaki ertelemeden ayırmaktadır. Erteleme öğrenmeyi olumsuz yönde etkileyebilir (Ackerman and Gross, 2005), kötü akademik 
performans ve psikolojik sıkıntı gibi olumsuz sonuçlara (Constantin, English and Mazmanian, 2017) sebep olabilir.

Ertelemenin öğrenmeyi olumsuz yönde etkileyebileceği, kötü akademik performans ve psikolojik sıkıntı gibi olumsuz sonuçlara sebep olabileceği yönünde araştırmalar bulunmaktadır. $\mathrm{Bu}$ nedenle, gelecekte öğrencilere rol model olacak öğretmen adaylarının akademik erteleme durumlarına yönelik çalışmanın faydalı olacağı düşünülmektedir.

Öğretmen adaylarının akademik erteleme durumları ile ilgili etkenlerin belirlenmesi onların bu sorunlarını daha iyi tanımalarına, çözüm önerileri üretmelerine yardımcı olacaktır. $\mathrm{Bu}$ durum, gerek öğrenim hayatlarında gerekse mesleki yaşamlarında daha verimli ve başarılı olmalarına katkıda bulunurken eğitim sistemine ve topluma yansıyan olumsuz sonuçlarının engellenmesi ve farkındalık yaratması açısından faydalı olacaktır.

Araştırmada, öğretmen adaylarının akademik erteleme davranışlarının farklı değişkenlere göre incelenmesi amaçlanmış ve bu amaç doğrultusunda aşağıdaki soruların yanıtları aranmıştır.

1. Öğretmen adaylarının anabilim dallarına göre akademik erteleme davranış puanları arasında anlamlı bir fark var midır?

2. Öğretmen adaylarının cinsiyete göre akademik erteleme davranış puanları arasında anlamlı bir fark var midır?

3. Öğretmen adaylarının akademik erteleme davranış puanları, akademik başarı durumuna göre farklılaşmakta mıdır?

4. Öğretmen adaylarının akademik erteleme davranış puanları, ikamet ettikleri yere (ailesinin yanı, yurt veya pansiyon, evde) göre farklılaşmakta mıdır?

\section{Yöntem}

Araştırma, tarama modelinde betimsel bir çalışmadır. İlişkisel tarama modeli iki ya da daha çok değişken arasındaki birlikte değişimin varlığının belirlenmesinin amaçlandığı tarama yaklaşımıdır (Karasar, 1984).

\section{Evren ve örneklem}

Çalışmanın evrenini, Cumhuriyet Üniversitesi Eğitim Fakültesinde öğrenim gören öğretmen adayları oluşturmaktadır. Uygun örneklem yöntemiyle belirlenen örneklem grubunu ise 2017-2018 eğitim öğretim yılında söz konusu fakültede öğrenim gören Fen Bilgisi, Türkçe, Sosyal Bilgiler ve Sınıf öğretmenliği anabilim dallarında öğrenim gören 263 öğretmen adayı oluşturmaktadır.

\section{Veri toplama araçları}


Öğretmen adaylarının akademik erteleme durumlarını belirlemek amacı ile "Akademik Erteleme Ölçeği” kullanılmıştır.

Akademik Erteleme Ölçeği (AEÖ): Ölçek Çakıcı (2003) tarafından geliştirilen 12'si olumsuz, 7'si $(1,4,7,9,11,13,17)$ olumlu toplam 19 maddeden oluşan beşli likert tipinde bir ölçektir. Bu ölçekte maddeler: "beni hiç yansıtmıyor”, “beni çok az yansıtıyor”, "beni biraz yansıtıyor", "beni çoğunlukla yansıtıyor”, “beni tamamen yansitıyor” şeklindedir. Ölçek tek yönlü puanlanmış olup "beni hiç yansıtmıyor" diyenler 1, "beni tamamen yansıtıyor” diyenler 5 puan alacak şekilde organize edilmiştir. Ölçekten en çok 95, en az 19 puan alınabilmektedir. Ölçekten alınacak yüksek puanlar, öğrencilerin akademik konularda erteleme davranışlarının yüksek olduğunu göstermektedir (Çakıcı, 2003). Ölçek için güvenirlik katsayısı Cronbach alpha .92 olarak bulunmuştur.

\section{Verilerin analizi}

Öğretmen adaylarının akademik erteleme durumları ve değişkenler arasında ilişki olup olmadığının belirlenmesi için istatiksel analiz yöntemlerinden, frekans, ortalama ve standart sapma değerleri ile tek yönlü ANOVA analizi kullanılmıştır.

\section{Bulgular}

\section{Alt Problem}

“Öğretmen adaylarının akademik erteleme davranış puanları arasında anlamlı bir fark var mıdır?" Şeklinde ifade edilen bu alt problemle ilgili olarak, öğrencilere AEÖ uygulanmıştır. Örneklem grubundan elde edilen verilerin .05 anlamlılık düzeyinde normallik varsayımının belirlenmesi için $n>50$ olanlar için Kolmogorov-Smirnov testi $n<50$ olanlar için ise shapirowilk testi kullanılmıştır. Uygulanma sonucunda elde edilen verilerin ( $\mathrm{p}_{\text {Fen }}=.687$; $\mathrm{p}_{\text {Türkçe }}=.160$; p $\left._{\text {Sosyal }}=.449 ; p_{\text {Sınıf }}=.092\right)$ normal dağılım ( $>$ >05) sergilediği belirlenmiştir. Varyansların homojenliğini incelemek için uygulanan Levene testi sonucunda ise $\mathrm{p}=.526$ ( $\mathrm{p}>.05)$ olarak hesaplanmıştır. Anlamlılık düzeyinin p>.05 olarak hesaplanması varyansların homojenliğinin sağlandığını göstermektedir. Gerekli varsayımlar sağlandıktan sonra anabilim dalına göre akademik erteleme puanları arasında anlamlı bir fark olup olmadığını belirlemek için tek faktörlü ANOVA uygulanmıştır. Elde edilen bulgular Tablo 1'de verilmiştir.

Tablo 1. Anabilim Dalına Göre Akademik Erteleme Puanlarının ANOVA Sonuçları

\begin{tabular}{|c|c|c|c|c|c|c|c|c|c|}
\hline \multicolumn{4}{|c|}{ Betimsel Değerler } & \multicolumn{6}{|c|}{ ANOVA Sonuçları } \\
\hline Grup & $\mathrm{N}$ & $\mathrm{x}$ & ss & $\begin{array}{l}\text { Varyans } \\
\text { K. }\end{array}$ & KT & $\mathrm{Sd}$ & $\mathrm{KO}$ & $\mathrm{F}$ & $\mathrm{p}$ \\
\hline Fen Bil. & 101 & 53,50 & 7,184 & G. aras1 & 510,103 & 3 & 170,034 & 2,679 &, 048 \\
\hline Türkçe & 54 & 55,76 & 8,105 & G. içi & 16950,646 & 259 & 63,477 & & \\
\hline
\end{tabular}




\begin{tabular}{lllllll}
\hline Sosyal Bil. & 75 & 56,63 & 8,236 & Toplam & 16440,543 & 262 \\
\hline Sinıf Öğr. & 33 & 56,39 & 9,317 & & & \\
\cline { 1 - 4 } Total & 263 & 55,22 & 8,043 & & & \\
\hline
\end{tabular}

Tablo 1 incelendiğinde öğretmen adaylarının akademik erteleme puanlarının ortalamanın üzerinde olduğu, \%95 güven aralığında $\mathrm{F}_{(3-259)}=2.679, \mathrm{p}=.48$ anabilim dalları arasında anlamlı düzeyde ( $\mathrm{p}<.05)$ fark olduğu görülmektedir.

$\mathrm{Bu}$ farkın hangi anabilim dalları arasında olduğunu belirlemek için Bonferroni testi uygulanmış, farkın fenbilgisi öğretmen adayları ile sosyal bilgiler öğretmenleri arasında olduğu belirlenmiştir. Ortalama puanlara bakıldığında sosyal bilgiler öğretmen adaylarının, fen bilgisi öğretmen adaylarına göre akademik ertelemeye puanlarının daha yüksek olduğu yani akademik ertelemeye daha meyilli oldukları görülmektedir.

\section{Alt Problem}

“Öğretmen adaylarının cinsiyete göre akademik erteleme davranış puanları arasında anlamlı bir fark var mıdır" Şeklinde ifade edilen bu alt problemle ilgili olarak, öğrencilere AEÖ uygulanmıştır. Örneklem grubundan elde edilen verilerin .05 anlamlılık düzeyinde normallik varsayımının belirlenmesi için Kolmogorov-Smirnov testi uygulanmış ve her iki gruptan elde edilen verilerin $\left(\mathrm{p}_{\mathrm{k} 1 \mathrm{z}}=.155 ; \mathrm{p}_{\text {erkek }}=.086\right)$ normal dağ1lım $(\mathrm{p}>.05)$ sergilediği belirlenmiştir. Varyansların homojenliğini incelemek için uygulanan Levene testi sonucunda ise $p=.555$ (p>.05) olarak hesaplanmıştır. Anlamlılık düzeyinin p>.05 olarak hesaplanması varyansların homojenliğinin sağlandığını göstermektedir. Gerekli varsayımlar sağlandıktan sonra cinsiyete göre akademik erteleme puanları arasında anlamlı bir fark olup olmadığını belirlemek için tek faktörlü ANOVA uygulanmıştır. Elde edilen bulgular Tablo 2'de verilmiştir.

Tablo 2. Cinsiyete Göre Akademik Erteleme Puanlarının ANOVA Sonuçları

\begin{tabular}{|c|c|c|c|c|c|c|c|c|c|}
\hline \multicolumn{4}{|c|}{ Betimsel Değerler } & \multicolumn{6}{|c|}{ ANOVA Sonuçları } \\
\hline Grup & $\mathrm{N}$ & $\mathrm{x}$ & SS & $\begin{array}{l}\text { Varyans } \\
\mathrm{K} \text {. }\end{array}$ & KT & $\mathrm{Sd}$ & $\mathrm{KO}$ & $\mathrm{F}$ & $\mathrm{p}$ \\
\hline $\mathrm{K}_{1 \mathrm{Z}}$ & 87 & 58,33 & 7,697 & $\begin{array}{l}\text { Gruplar } \\
\text { aras1 }\end{array}$ & 1262,773 & 1 & 1262,773 & 21,009 & ,001 \\
\hline Erkek & 176 & 53,68 & 7,780 & $\begin{array}{l}\text { Gruplar } \\
\text { içi }\end{array}$ & 15687,873 & 261 & 60,107 & & \\
\hline Toplam & 263 & 55,22 & 8,043 & Toplam & 16950,646 & 262 & & & \\
\hline
\end{tabular}

Tablo 2 incelendiğinde cinsiyete göre akademik erteleme puanları arasında \%95 güven aralığında anlamlı düzeyde $(\mathrm{p}<.05)$ fark olduğu görülmektedir. Akademik erteleme puanları ortalamasına bakıldığında kızların $(x=58,33)$ ortalama puanlarının daha yüksek olduğu, yani erkeklere göre daha fazla akademik ertelemeye sahip oldukları görülmektedir. 


\section{Alt Problem}

"Öğretmen adaylarının akademik erteleme davranış puanları, akademik başarı durumuna göre farklılaşmakta mıdır?" Şeklinde ifade edilen bu alt problemle ilgili olarak Örneklem grubundan elde edilen verilerin .05 anlamlılık düzeyinde normallik varsayımının belirlenmesi için Kolmogorov-Smirnov testi uygulanmış ve her iki gruplan elde edilen verilerin $\left(\mathrm{p}_{1.00-2.00}=.785 ; \mathrm{p}_{2.01-3.00}=.052 ; \mathrm{p}_{3.01-4.00}=.603\right)$ normal dağılım $(\mathrm{p}>.05)$ sergilediği belirlenmiştir. Varyansların homojenliğini incelemek için uygulanan Levene testi sonucunda ise $p=.616$ ( $\mathrm{p}>.05$ ) olarak hesaplanmıştır. Anlamlılık düzeyinin $\mathrm{p}>.05$ olarak hesaplanması varyansların homojenliğinin sağlandığını göstermektedir. Gerekli varsayımlar sağlandıktan sonra akademik başarı ile akademik erteleme puanları arasında anlamlı bir fark olup olmadığını belirlemek için tek faktörlü ANOVA uygulanmıştır. Elde edilen bulgular Tablo 3'de verilmiştir.

Tablo 3. Akademik Erteleme Davranışları İle Akademik Başarı Durumlarına İlişkin ANOVA Sonuçları

\begin{tabular}{|c|c|c|c|c|c|c|c|c|c|}
\hline \multicolumn{4}{|c|}{ Betimsel Değerler } & \multicolumn{6}{|c|}{ ANOVA Sonuçları } \\
\hline $\begin{array}{l}\text { Puan } \\
\text { Aralığ } 1\end{array}$ & $\mathrm{~N}$ & $\mathrm{x}$ & ss & $\begin{array}{l}\text { Varyans } \\
\mathrm{K} \text {. }\end{array}$ & KT & $\mathrm{Sd}$ & $\mathrm{KO}$ & $\mathrm{F}$ & $\mathrm{p}$ \\
\hline $\begin{array}{l}1.00- \\
2.00\end{array}$ & 12 & 57,58 & 6,543 & $\begin{array}{l}\text { Gruplar } \\
\text { aras1 }\end{array}$ & 88,629 & 2 & 44,315 & ,683 & ,506 \\
\hline $\begin{array}{l}2.01- \\
3.00\end{array}$ & 183 & 55,27 & 8,109 & $\begin{array}{l}\text { Gruplar } \\
\text { içi }\end{array}$ & 16862,017 & 260 & 64,854 & & \\
\hline $\begin{array}{l}3.01- \\
4.00\end{array}$ & 68 & 54,66 & 8,125 & Toplam & 16950,646 & 262 & & & \\
\hline Top. & 263 & 55,22 & 8,043 & & & & & & \\
\hline
\end{tabular}

Tablo 3 incelendiğinde, öğretmen adaylarının akademik başarı durumlarına göre akademik erteleme puanları arasında p>.05 anlamlı düzeyde bir fark olmadığ 1 görülmektedir.

\section{Alt Problem}

“Öğretmen adaylarının akademik erteleme davranış puanları, ikamet ettikleri yere (Ailesinin yanı, yurt veya pansiyon, evde) göre farklılaşmakta mıdır?" Şeklinde ifade edilen bu alt problemle ilgili olarak Örneklem grubundan elde edilen verilerin .05 anlamlılık düzeyinde normallik varsayımının belirlenmesi için $\mathrm{n}>50$ olanlar için Kolmogorov-Smirnov testi $\mathrm{n}<50$ olanlar için ise shapirowilk testi kullanılmıştır. Uygulanma sonucunda elde edilen verilerin ( $\mathrm{p}_{\text {Aile }}=.185 ;$ pYurt=.146; $\left.\mathrm{p}_{\mathrm{Ev}}=.426\right)$ normal dağılım ( $\left.\mathrm{p}>.05\right)$ sergilediği belirlenmiştir. Varyansların homojenliğini incelemek için uygulanan Levene testi sonucunda ise $\mathrm{p}=.616$ ( $>$ >.05) olarak hesaplanmıştır. Anlamlılık düzeyinin $\mathrm{p}>.05$ olarak hesaplanması varyansların homojenliğinin sağlandığını göstermektedir. Gerekli varsayımlar sağlandıktan sonra ikamet 
edilen yer ile akademik erteleme puanları arasında anlamlı bir fark olup olmadığını belirlemek için tek faktörlü ANOVA uygulanmıştır. Elde edilen bulgular Tablo 4'de verilmiştir.

Tablo 4. Akademik Erteleme Davranışları İle İkamet Ettikleri Yere İlişskin ANOVA Sonuçları

\begin{tabular}{|c|c|c|c|c|c|c|c|c|c|}
\hline \multicolumn{3}{|c|}{ Betimsel Değerler } & \multicolumn{7}{|c|}{ ANOVA Sonuçları } \\
\hline Grup & $\mathrm{N}$ & $\mathrm{x}$ & ss & $\begin{array}{l}\text { Varyans } \\
\mathrm{K} \text {. }\end{array}$ & KT & $\mathrm{Sd}$ & $\mathrm{KO}$ & $\mathrm{F}$ & $\mathrm{p}$ \\
\hline $\begin{array}{l}\text { Ailesinin } \\
\text { yanı }\end{array}$ & 70 & 55,09 & 8,944 & $\begin{array}{l}\text { Gruplar } \\
\text { aras1 }\end{array}$ & 217,372 & 2 & 108,686 & 1,689 & , 187 \\
\hline $\begin{array}{l}\text { Yurt } \\
\text { Pansiyon }\end{array}$ & 146 & 54,66 & 7,982 & $\begin{array}{l}\text { Gruplar } \\
\text { içi }\end{array}$ & 16733,275 & 260 & 64,359 & & \\
\hline $\mathrm{Ev}$ & 47 & 57,13 & 6,553 & Toplam & 16950,646 & 2 & & & \\
\hline Toplam & 263 & 55,22 & 8,045 & & & & & & \\
\hline
\end{tabular}

Tablo 4'e göre, öğretmen adaylarının ikamet ettikleri yer ile akademik erteleme puanları arasında $\mathrm{p}>.05$ anlamlı düzeyde bir fark olmadığı görülmektedir.

\section{Sonuç, tartışma ve öneriler}

Yapılan analizler sonucunda, öğretmen adaylarının akademik erteleme puanlarının ortalamanın üzerinde olduğu, ortalama puanlara bakıldığında sosyal bilgiler öğretmen adaylarının, fen bilgisi öğretmen adaylarına göre akademik ertelemeye daha yatkın oldukları görülmüştür.

Akademik erteleme davranışlarına yönelik ilgili araştırmalar incelendiğinde; öğrencilerin başarısızlık korkusunun, akademik erteleme davranışlarını açıklamada önemli bir değişken olduğu (Fatimah et al., 2011; Özer ve Altun, 2011), benlik saygısının akademik ertelemeyi olumsuz yönde etkilediği (Çakıcı, 2003; Ferrari et al., 2007; Kandemir, 2010; Solomon and Rothblum, 1984), öğrencilerin durumluluk kaygısının artması ile akademik erteleme davranışlarının da arttığı (Aydoğan ve Özbay, 2012; Lay and Silverman, 1996) Güdülenme düzeyi düşük olan bireylerin akademik ertelemeye daha meyilli oldukları (Brownlow and Reasinger, 2000; Cohen, Ferrari and Díaz-Morales, 2008; Lee, 2005; Senecal, Koestner and Vallerand, 1995; Tuckman, 1998; Tuckman and Sexton, 1989) ve özyeterlik inancı ile negatif yönde anlamlı bir ilişkinin olduğu (Aydoğan ve Özbay, 2012; Chow 2011 Ferrari, Parker and Ware, 1992; Haycock, McCarthy and Skay, 1998; Klassen, Krawchuk and Rajani, 2007; Steel, 2007; Wang et al., 2011; Wolters, 2003) yönünde bulgulara ulaşıldığ1 görülmektedir.

Öğretmen adaylarının anabilim dallarına göre akademik erteleme durumlarına ilişkin Balkıs (2007) çalışmasında, sayısal puan türüne göre öğrenci alan bölümlerde öğrenim gören öğretmen adaylarının akademik erteleme düzeylerinin, sözel ve eşit ağırlık puan türüne göre öğrenci alan alanlarda öğenim gören öğretmen adaylarının akademik erteleme düzeylerinden 
daha yüksek olduğunu ifade etmiştir. Öğretmen adaylarının anabilim dallarına göre akademik erteleme durumlarına ilişkin yapılan çalışmanın sınırlı olması ve bu çalışmada elde edilen sonuçların Balkıs (2007) tarafından elde edilen sonuçlarla farklı olması nedeniyle öğretmen adaylarının akademik erteleme durumlarının öğrenim gördükleri alanın sayısal, sözel veya eşit ağırlıklı olmasına göre bir genellemenin yapılamayacağı düşünülmektedir. Bu konuda daha net sonuçlara ulaşma açısından araştırma sayılarının artmasına ihtiyaç olduğu açıktır.

Bir diğer bulgu öğretmen adaylarının cinsiyete göre akademik erteleme puanları arasında anlamlı bir farkın olduğu ve bu farka göre kız öğrencilerin akademik erteleme eğilimlerinin erkek öğrencilere göre daha yüksek olduğu yönündedir.

İlgili alan yazın incelendiğinde araştırma sonuçları ile benzer doğrultuda bulgulara ulaşılan (Adesina, 2011; Akkaya, 2007; Özer ve Ferrari, 2011) araştırmalar olmakla birlikte, erkek öğrencilerin akademik erteleme eğilimlerinin kız öğrencilere göre daha yüksek olduğu yönünde (Akbay, 2009; Aydoğan ve Özbay, 2012; Balkıs ve Duru, 2009; Kandemir, 2010; Sarığlu, 2011; Tanrıkulu, 2013) bulguların elde edildiği araştırmaların olduğu ve üçüncü ihtimal olan cinsiyete göre anlamlı bir farkın olmaması yönünde de bulguların elde edildiği (Aydoğan, 2008; Beswick et al., 1988; Haycock, McCarty and Skay, 1998; Kim and Seo, 2015; Watson, 2001; Zarick and Stonebraker, 2009) çalışmaların olduğu görülmektedir.

Bir diğer bulgu ise öğretmen adaylarının akademik başarı durumlarına göre akademik erteleme puanları arasında anlamlı düzeyde bir fark olmadığı yönündedir.

Yapılan araştırmalar incelendiğinde, akademik başarısı düşük olan öğretmen adaylarının akademik erteleme düzeylerinin daha yüksek olduğu (Balkıs, 2007; Fritzsche and Tuckman,1998; Young and Hickson, 2003) yani ters yönlü bir ilişkinin olduğu yönünde bulgulara ulaşıldığı görülmektedir. Bu çalışmada da düşük akademik puana sahip öğrencilerin akademik erteleme puanları, akademik başarı puanı yüksek öğrencilere göre daha yüksek olduğu ancak istatiksel olarak anlamlı bir farkın olmadığı görülmüştür. Literatürdeki sonuçlar arasındaki bu farkın örneklem grubunun büyüklügünden kaynaklanmış olabileceği düşünülmektedir.

Araştırmanın son bulgusu ise öğretmen adaylarının ikamet ettikleri yer (Ailesinin yanı, yut veya pansiyon, evde) ile akademik erteleme puanları arasında anlamlı bir fark olmadığı yönündedir.

$\mathrm{Bu}$ araştırmadan ve literatürden elden edilen bilgiler doğrultusunda akademik ertelemenin önemli bir problem olduğu ve bu durumun ortaya çıkmasını sağlayan etkenler arasında başarısızlık korkusu, benlik saygısı, özyeterlik inancı, durumluluk kaygısının artması ve Güdülenme düzeyi gibi faktörlerin etkili olduğu belirtilirken, cinsiyetin akademik erteleme 
üzerine etkisini belirlemek üzere yapılan araştırmalarda farklı sonuçlara ulaşıldığı ve ortak bir sonucun ortaya çıkmadığı görülmektedir. Cinsiyet Konusunda elde edilen bu farklı bulgular, çeşitli örneklem grupları ile toplumsal farklılıklar da göz önüne alınarak kapsamlı çalışmalara gerek duyulduğunu göstermektedir.

Akademik ertelemenin öğretmen adayları arasında yaygın düzeyde olduğu görülmektedir. Bu problemin nedenlerin araştırılmasına yönelik, daha geniş örneklem grupları ve farklı kültür yapıları da dikkate alınarak nicel araştırmalarla birlikte nitel çalışmaların da yapılması faydalı olacaktır.

\section{Kaynaklar}

Ackerman, D. S. and Gross, B. L. (2005). My instructor made me do it: Task characteristics of procrastination Journal of Marketing Education, 27(1), 5-13.

Adesina, O. J. (2011). Influence of personality types and academic procrastination on the academic achievements of senior secondary school adolescents in ibadan. IFE Psycholog IA,19(1).

Akbay, E. S. (2009). Cinsiyete göre üniversite öğrencilerinde akademik erteleme davranışı: akademik güdülenme, akademik öz yeterlik ve akademik yükleme stillerinin rolü. Yayımlanmamış Yüksek Lisans Tezi. Mersin Üniversitesi, Sosyal Bilimler Enstitüsü, Mersin.

Akkaya, E. (2007). Academic procrastination among faculty of education students: The role of gender, age, academic achievement, perfectionism and depression. Yayımlanmamış Yüksek Lisans Tezi. Ortadoğu Teknik Üniversitesi, Sosyal Bilimler Enstitüsü, Ankara.

Alexander, E. S. and Onwuegbuzie, A. J. (2007). Academic procrastination and the role of hope as a coping strategy. Personality and Individual Differences, 42, 1301-1310.

Aydoğan, D. (2008). Akademik erteleme davranışının benlik saygısl, durumluk kaygı ve öz yeterliliği ile açıklana bilirliği. Yayımlanmamış Yüksek Lisans Tezi. Gazi Üniversitesi, Eğitim Bilimleri Enstitüsü, Ankara.

Aydoğan, D. ve Özbay, Y. (2012). Akademik erteleme davranışının benlik saygısı, durumluluk kaygı, öz-yeterlilik açısından açıklana bilirliğinin incelenmesi. Pegem Eğitim ve Öğretim Dergisi, 2(3), 1-9

Balkıs, M. (2007). Öğretmen adaylarının davranışlarındaki erteleme eğiliminin, karar verme stilleri ile ilişkisi. Pamukkale Üniversitesi Eğitim Fakültesi Dergisi, 21(1),67-83

Balkıs, M. ve Duru, E. (2009). Prevalence of academic procrastination behavior among preservice teachers, and its relationship with demographic and individual preferences. Journal of Theory and Practice in Education, 5(1), 18-32. 
Beswick, G., Rothblum, E. and Mann, L. (1988). Psychological antecedents of student procrastination. Australian Psychologist, 23(2), 207-217.

Briody, R. (1980). An exploratory study of procrastination (Doctoral dissertation, Brandeis University, 1980). Dissertation Abstracts International, 41, 590.

Brownlow, S. and Reasinger, R. D. (2000). Putting off until tomorrow what is better done today: Academic procrastination as a function of motivation toward college work. Journal of Social Behavior and Personality, 15 (5), 15-34

Chu, A. H. and Choi J. N. (2005). Rethinking procrastination: positive effects of"Active" procrastination behavior on attitudes and performance. J.Soc. Psychol, 145(3), 245-264.

Chow, H. P. H. (2011). Procrastination among undergraduate students: Effects of emotional intelligence, school life, self-evaluation, and self- efficacy. Alberta Journal of Educational Research, 57(2), 234-240.

Cohen J. R., Ferrari J. R. and Díaz-Morales, J. F. (2008). An integrated view of personality styles related to avoidant procrastination. Personality and Individual Differences, 45, $554-558$.

Constantin, K., English, M. M. and Mazmanian, D. (2017). Anxiety, depression, and procrastination among students: Rumination plays a larger mediating role than worry, Journal of Rational-Emotive \& Cognitive-Behavior Therapy, 35, 1-13.

Çakıc1, Ç. D. (2003). Lise ve üniversite ögrencilerinde genel erteleme ve akademik erteleme davranışının incelenmesi. Yayımlanmamış Yüksek Lisans Tezi. Ankara Üniversitesi, Eğitim Bilimleri Enstitüsü, Ankara

Ellis, A. and Knaus, W. J. (1977). Overcoming procrastination. New York: Signet Books

Fatimah, O., Lukman, Z.M., Khairudin, R., Shahrazad W. S. and Halim, W, F. (2011). Procrastination's relation with fear of failure, competence expectancy and intrinsic motivation. Pertanika J. Soc. Sci. \& Hum, 19(S), 123-127

Ferrari, J. R., Johnson, J. L. and McCown, W. G. (1995). Procrastination and task avoidance: Theory, Research and Treatment. New York : Plenum Press.

Ferrari, J. R., Parker, J. T. and Ware, C. B. (1992). Academic procrastination: Personality correlates with Myers-Briggs types, self-efficacy, and academic locus of control. Journal of Social Behavior \& Personality, 7(3), 495-502.

Fritzsche, B. A., Young, B. R. and Hickson, K. C. (2003). Individual differences in academic procrastination tendency and writing success. Personality and Individual Differences $35,1549-1557$ 
Gülebağlan, C. (2003). Öğretmenlerin işleri son ana erteleme ĕgilimlerinin, mesleki yeterlilik algıları, mesleki deneyimleri ve branşları bakımından karşılaştırılmasına yönelik bir araştırma. Yayımlanmamış Yüksek Lisans Tezi. Ankara Üniversitesi, Eğitim Bilimleri Enstitüsü, Ankara

Haycock, L. A., Mccarthy, P. and Skay, C. L. (1998). Procrastination in college students: The role of self-efficacy and anxiety. Journal of Counseling and Development, 76, 317-324.

Howell, A. and Watson, D. C. ( 2007 ). Procrastination: Associations with achievement goal orientation and learning strategies. Personality and individual differences, 43, 167-178.

Kandemir, M. (2010). Akademik erteleme davranısını açıklayıcı bir model. Yayımlanmamıs Doktora Tezi, Gazi Üniversitesi, Ankara.

Karasar, N. (1984). Bilimsel araştırma metodu. Ankara: Hacetepe Taş Kitapçılık.

Kim, K. R. and Seo, E. H. (2015). The relationship between procrastination and academic performance: A meta-analysis. Personality and Individual Differences, 82, 26-33.

Klassen, R. M., Krawchuk, L. L. and Rajani, S. (2007). Academic procrastination of undergraduates low self-efficacy to self-regulate predicts higher levels of procrastination. Contemporary Educational Psychology, 33, 915-931.

Lay, C. H. and Silverman, S. (1996). Trait procrastination anxiety, and dilatory behavior. Personality and Individual Differences, 21(1), 61-67.

Lee, E. (2005). The relationship of motivation and flow experience to academic procrastination in university students. Journal of Genetic Psychology, 166, 5-14.

Milgram, N., Mey-Tal, G. and Levison, Y. (1998). Procrastination, generalized or specific, in college students and their parents. Personality and individual differences, 25, 297-3 16.

O'Brien, W. K. (2002). Applying the transtheoretical model to academic procrastination. Doctoral Dissertation, University of Houston.

Özer, A. ve Altun, E. (2011). Üniversite öğrencilerinin akademik erteleme nedenleri. Mehmet Akif Ersoy Üniversitesi Ĕ̈itim Fakültesi Dergisi, 21, 45-72

Rosario, P., Costa, M., Núñez, J. C., González-Pienda, J., Solano, P. and Valle, A. (2009). Academic procrastination: associations with personal, school and family variables. Spanish Journal of Psychology, 12(1), 118-127.

Sarığlu, A. F. (2011). Öğretmen adaylarının akademik erteleme ĕgilimi ile mükemmelliyetçilik düzeyleri arasındaki ilişkinin incelenmesi. Yayımlanmamış Yüksek Lisans Tezi. İstanbul Üniversitesi, Sosyal Bilimler Enstitüsü, İstanbul. 
Sadeghi, H., Hajloo, N. and Emami, F. (2011). The study of relationship between obsessive beliefs andprocrastination among students of Mohagheghe ardabili and Marageh universities Procedia. Social and Behavioral Sciences, 30, 292 - 296.

Senecal, C., Koestner, R. and Vallerand, R. J. (1995). Self-regulation and academic procrastination. Journal of Social Psychology, 135, 607-619.

Schouwenburg, H. C., Lay, C., Pychyl, T. A. and Ferrari, J. R. (2004). Counseling the procrastinator in academic settings. American Psychological Association. Washington, $D C$.

Solomon, L. J. and Rothblum, E. D. (1984). Academic procrastination: frequency and cognitive behavioral correlates. Journal of Counseling Psychology, 31(4), 503-509.

Steel, P. (2007). The nature of procrastination: A meta-analytic and theoretical review of quintessential self-regularty failure. Psychological Bulletin, 133 (1), 65-94.

Tanrıkulu, M. (2013). Ergenlerin akademik erteleme davranışlarıyla benlik saygılarının incelenmesi. Yayımlanmamış Yüksek Lisans Tezi. Dokuz Eylül Üniversitesi, Eğitim Bilimleri Enstitüsü, İzmir.

Tuckman, B. W. (1998). Using tests as an incentive to motivate procrastinators to study. Journal of Experimental Education, 2, 141-47.

Tuckman, B. W. and Sexton, T. L. (1992). Self-believers are self-motivated; self-doubters are not. Personality and Individual Differences, 13, 425-428.

Wang, M., Qian, M., Wang, W. and Chen, R. (2011). Effects of group counseling based on selfefficacy for self-regulated learning in students with academic procrastination. Chinese Mental Health Journal, 25(12), 921-926.

Watson, D. C. (2001). Procrastination and the five-factors model: A facet level analysis. Personality and Individual Differences, 30, 149-158

Wolters, C. A. (2003). Understanding procrastination from a self-regulated learning perspective. Journal of Educational Psychology, 95(1), 179-187.

Zarick, L. M. and Stonebraker, R. (2009). I'll do it tomorrow: the logic of procrastination. College Teaching, 57(4), 211-215. 